\author{
Marquette University \\ e-Publications@Marquette
}

$10-10-2013$

\title{
Conditional Spectrum-Based Ground Motion Selection. Part II: Intensity-Based Assessments and Evaluation of Alternative Target Spectra
}

Ting Lin

Marquette University, ting.lin@marquette.edu

Curt B. Haselton

California State University - Chico

Jack W. Baker

Stanford University

Follow this and additional works at: https://epublications.marquette.edu/civengin_fac

Part of the Civil and Environmental Engineering Commons

\section{Recommended Citation}

Lin, Ting; Haselton, Curt B.; and Baker, Jack W., "Conditional Spectrum-Based Ground Motion Selection. Part II: Intensity-Based Assessments and Evaluation of Alternative Target Spectra" (2013). Civil and Environmental Engineering Faculty Research and Publications. 10.

https://epublications.marquette.edu/civengin_fac/10 


\title{
Conditional Spectrum-Based Ground Motion Selection. Part II: Intensity- Based Assessments and Evaluation of Alternative Target Spectra
}

\author{
Ting Lin \\ Department of Civil and Environmental Engineering \\ Stanford University \\ Stanford, $C A$ \\ Curt B. Haselton \\ Department of Civil Engineering \\ California State University, Chico \\ Chico, CA \\ Jack W. Baker \\ Department of Civil and Environmental Engineering \\ Stanford University \\ Stanford, $C A$
}

Summary: In a companion paper, an overview and problem definition was presented for ground motion selection on the basis of the conditional spectrum (CS), to perform risk-based assessments (which estimate the annual rate of exceeding a specified structural response amplitude) for a 20story reinforced concrete frame structure. Here, the methodology is repeated for intensity-based assessments (which estimate structural response for ground motions with a specified intensity level) to determine the effect of conditioning period. Additionally, intensity-based and risk-based assessments are evaluated for two other possible target spectra, specifically the uniform 
hazard spectrum (UHS) and the conditional mean spectrum (CMS, without variability).It is demonstrated for the structure considered that the choice of conditioning period in the CS can substantially impact structural response estimates in an intensity-based assessment. When used for intensity-based assessments, the UHS typically results in equal or higher median estimates of structural response than the CS; the CMS results in similar median estimates of structural response compared with the CS but exhibits lower dispersion because of the omission of variability. The choice of target spectrum is then evaluated for risk-based assessments, showing that the UHS results in overestimation of structural response hazard, whereas the CMS results in underestimation. Additional analyses are completed for other structures to confirm the generality of the conclusions here. These findings have potentially important implications both for the intensity-based seismic assessments using the CS in future building codes and the risk-based seismic assessments typically used in performance-based earthquake engineering applications.

\section{Introduction}

Ground motion selection provides important seismic input to nonlinear dynamic analysis that is used to predict structural performance typically on the basis of structural response parameters that are of most interest. The uncertainty in ground motion input typically accounts for a significant portion of the uncertainty in structural response output. To determine what ground motions would be appropriate for nonlinear dynamic analysis, we need to be clear about the structural analysis objective as well as the target response spectrum for which ground motions are selected and scaled to match. Nonlinear dynamic analysis can be carried out with the objectives of intensity-based (which estimates structural response given ground motions with a specified intensity level) [1] and risk-based (which estimates the mean annual rate of exceeding a specified structural response amplitude) assessments on the structural response of interest (which may include peak story drift ratio ( $P S D R$ ), peak floor acceleration (PFA), single-story engineering demand parameter (EDP), member forces, or any other EDP of interest). Target response spectra may include most commonly the uniform hazard spectrum (UHS) that corresponds to spectral accelerations ( $\mathrm{Sa}$ ) with equal probabilities of exceedance at all periods, and more recently the conditional mean spectrum (CMS) or the conditional spectrum (CS) that accounts for the correlations between Sa values across periods. Depending on the structural analysis objective and the target response spectrum, conclusions regarding structural performance may differ, and it is 
important to investigate such impacts to provide ground motion selection insights for future nonlinear dynamic analysis.

The companion paper [2] outlines the ground motion selection procedures for risk-based assessments using the CS with a range of conditioning periods and highlights the importance of hazard consistency in the selected ground motions. While risk-based assessments of structural response directly account for the uncertainty in ground motion hazard by considering different intensity levels and their corresponding occurrence rates, intensity-based assessments are used in practice as a simpler option to fulfill building code requirements $[$ e.g., $[3,4]]$, which are mainly concerned with structural response at a specified intensity level, for example, Sa associated with $2 \%$ in 50 years or $10 \%$ in 50 years probabilities of exceedance. In this paper, we focus on the structural analysis objective of intensity-based assessments, with ground motions selected using the CS at various conditioning periods, to examine the impact of conditioning period on intensity-based assessments.

The CS was used as the target response spectrum for which ground motions were selected and scaled to match in the companion paper [2] . The CS accounts for both the mean and the variability of the ground motion spectra and is proposed as an appropriate target for risk-based assessments $[\underline{5,6]}$. In practice, the UHS is more commonly used, especially through building codes [e.g., $[3,4,7]]$. However, shortcomings of the UHS include a lack of hazard consistency as it assumes the occurrence of high spectral values at all periods [e.g., [ $\underline{8-12]}]$. Alternatively, the CMS is used to better capture the hazard information [e.g., [12-16]]. However, the CMS does not account for the variability of the ground motion spectra. In this paper, the UHS and CMS are used as target spectra to select ground motions, and their corresponding structural analysis results are compared with those using the CS, to examine the impact of target spectrum on structural response estimates.

The same 20-story reinforced concrete perimeter frame structure $[17,18]$ located in Palo Alto, California as used in the companion paper [2] is used for illustration. In Section 2, structural analyses are carried out with the objectives of intensity-based in addition to risk-based assessments on the structural response of 
interest (which include PSDR and PFA). Such nonlinear dynamic analyses are repeated for the CS at various conditioning periods to examine the impact of conditioning period in Section 3 , and additionally for the UHS and the CMS to examine the impact of target spectrum in Section 4 . To verify the observations earlier, more generally, one additional four-story structure was analyzed using the same procedure with ground motions selected to match CS in Section 5. Finally, implications of the choice of conditioning period and target spectrum for building-code-type check and performance-based earthquake engineering are discussed in Section 6.

\section{Analysis Objectives}

Ground motions represent an important source of uncertainty in nonlinear dynamic analysis. Before analyzing structural response results or even selecting ground motions, it is important to ask the question: 'What is the objective of the structural analysis?' Changing the question we ask (intensity-based or risk-based assessments) would essentially change the ground motion inputs we need and the structural response answers we get.

\subsection{Risk-based assessments}

Risk-based assessments using CS as a target spectrum with varying conditioning periods were introduced in the companion paper [2]. Detailed procedures and results were presented for risk-based assessments on the basis of PSDR as an EDP, followed by brief illustrations with alternative EDPs that include PFA, single-story story drift ratio, and single-story floor acceleration. If an exact CS (which incorporates multiple earthquake sources and multiple ground motion prediction models) is used, risk-based assessment results are relatively insensitive to the choice of conditioning period, and the same set of ground motions can be used to assess any structural response of interest. In practice, however, if we use an approximate CS, we may need to adjust the target spectrum to account for spectral variability further away from the conditioning period to ensure the correct distribution for the period most important to each EDP. This is because an exact CS already correctly accounts for the spectral variability at all 
periods of interest and thereby covers EDPs of interest without any further adjustments.

When the structural analysis objective is changed to an intensity-based assessment, which is only concerned with structural response at a given ground motion intensity level without consideration of ground motion occurrence rates, the choice of conditioning period in the CS may matter as we essentially change the question being asked. Here, the focus is on the intensity-based assessment, and its difference from the risk-based assessment is highlighted, together with how it is impacted by the choice of conditioning period through ground motions selected and scaled using the CS at various conditioning periods.

\subsection{Intensity-based assessments}

An intensity-based assessment differs from a risk-based assessment in its analysis goal, and its procedures are in fact covered by the risk-based assessment. An intensity-based assessment is basically the first part of a risk-based assessment that looks at structural response at a given intensity level, without integration with seismic hazard curves. From structural analysis at a given intensity level, structural response parameters of interest (e.g., PSDR or PFA) are obtained, and their logarithmic mean, $\mu_{\text {InEDP, }}$ and logarithmic standard deviation (also referred to as dispersion), $\sigma_{\text {InEDP, }}$ are estimated, along with probability of collapse, $P(C)$. A lognormal distribution can be used to fit the structural response parameters at each intensity level [e.g., [19-24]]. The empirical probability of collapse at each intensity level can be computed by counting the number of collapses and dividing by the total number of analyses.

Here is another way to look at the difference based on the output. A risk-based assessment yields one number regarding the 'risk' for each EDP level, that is, the rate of exceedance, $\lambda(E D P>y)$ (by considering various intensity levels and EDP distribution at each intensity level). The results from risk-based assessments are found to be relatively insensitive to the choice of conditioning period, as illustrated by Table I in the companion paper [2] . Conversely, an intensity-based assessment yields information about EDP estimates (e.g., median and dispersion of EDP) at each intensity level (without 
considerations of multiple intensity levels and their occurrence rates). The results from intensity-based assessments will be presented later in Section 3.

The target spectrum in building codes $[$ e.g., $[3,4,7]]$ is often on the basis of the UHS at one intensity level over a range of periods, for example, $0.2-1.5 T_{1}$, that covers the first-mode period of the structure as well as higher modes and lengthened periods because of nonlinear behavior. The UHS assumes equal probability of exceedance of Sa at all periods. This differs from the CS that accounts for correlations between Sa pairs at different periods, and essentially represents the distribution of $\mathrm{Sa}$ at all periods given $\mathrm{Sa}$ at one period, that is, the conditioning period. If the CS is used instead of the UHS, it is not obvious which period to choose as the conditioning period if structural response is examined at only one intensity level. To examine the effect of conditioning period on intensity-based assessments, a range of conditioning periods are used at multiple intensity levels.

\section{Impact of Conditioning Period On Intensity- Based Assessments Using the Conditional Spectrum}

To illustrate, sets of 40 ground motions are selected for the 20story perimeter frame at 10 intensity levels, using the CS at four conditioning periods. The conditioning periods, $T^{*}$, cover the structure's first three modal periods $\left(T_{1}=2.6 \mathrm{~s}, T_{2}=0.85 \mathrm{~s}\right.$, and $T_{3}=0.45 \mathrm{~s}$ ) and up to approximately twice the first-mode period $\left(2 T_{1}=5 \mathrm{~s}\right.$ ). Each set of 40 ground motions correspond to one intensity level and one conditioning period. In the companion paper [2] , Figures 7(a) and (b) show the distribution of PSDR and probability of collapse respectively at 10 intensity levels for the conditioning period $T^{*}$ $=2.6 \mathrm{~s}$. On the basis of fitting a lognormal distribution to the empirical PSDR results, the logarithmic mean and standard deviation of PSDR are shown as a function of $\mathrm{Sa}\left(T^{*}\right)$ in Figure $\underline{7}(\mathrm{a})$. Alternatively, the logarithmic mean and standard deviation of EDPs can be plotted as a function of ground motion intensity level for various conditioning periods, to investigate the effect of different conditioning periods on intensity-based assessments. Figure $\underline{7}$ (b) shows the observed fractions of collapse at each $\mathrm{Sa}\left(T^{*}\right)$ level, and a lognormal collapse fragility 
obtained on the basis of the maximum-likelihood method [e.g., [21, $25,26]]$. Similarly, probability of collapse can be plotted as a function of intensity level when multiple conditioning periods are considered.

Intensity-based calculations for PSDR, PFA, and probability of collapse given 10 spectral amplitudes (corresponding to 10 specified exceedance rates) for ground motions selected to match the CS at various conditioning periods are shown in Figure $\underline{1}$ and Table $\underline{1}$. As Sa associated with each exceedance rate vary among conditioning periods, all structural response results are plotted against return period, which is fixed for each intensity level regardless of its corresponding Sa. Figures $\underline{1}$ (a) and (b) show the median PSDR and logarithmic standard deviation of non-collapse PSDR until the exceedance rate corresponding to an $\mathrm{Sa}\left(T^{*}\right)$ level results in 50\% collapse. Here, the solid line $\left(T^{*}=2.6 \mathrm{~s}\right)$ in Figure $\underline{1}(\mathrm{a})$ is equivalent to connecting the median values of PSDR at various intensity levels in Figure $\underline{7}(a)$ in the companion paper [2] , except that the $x$-axis is return period in years instead of $\mathrm{Sa}\left(T^{*}\right)$ in $\mathrm{g}$. Also shown in $\mathrm{A} \underline{1}$ (a) are median PSDR results from analyses using CS with three other conditioning periods for comparison. Similarly, the solid line $\left(T^{*}=2.6 \mathrm{~s}\right)$ in Figure $\underline{1}(\mathrm{~b})$ is equivalent to connecting the logarithmic standard deviation values of non-collapse PSDR at various intensity levels (up to $50 \%$ collapse) in Figure $\underline{7}(\mathrm{a}$ ) in the companion paper [ㄹ], superimposed with results from three other conditioning periods. At the $\mathrm{Sa}\left(T^{*}\right)$ levels corresponding to greater than $50 \%$ probability of collapse, the median PSDR is governed by the collapse PSDR, and therefore, is not illustrated here. Similarly, the logarithmic standard deviation of non-collapse PSDR is not informative at high probability of collapse, and therefore, is cut off when $50 \%$ or more of the analyses cause collapse. Figures $\underline{1}$ (c) and (d) show the median and logarithmic standard deviation of PFA. In the case of collapse (except for collapse mechanisms that cause partial collapse in the upper floors), PFA is substituted by the peak ground acceleration ( $P G A)$ of individual ground motion (corresponding to the ground floor acceleration) [23]. Figure 1 (e) shows the probabilities of collapse obtained from these analyses.

As is evident from Figure $\underline{1}$ and Table $\underline{1}$, the structural responses at each intensity level are generally different among various conditioning periods, with differences of a factor of four or more being 
observed between results from varying conditioning periods. For instance, at shorter return periods (lower spectral amplitudes), the median PSDR shows a slight discrepancy among the conditioning periods (e.g., about 50\% difference between 0.008 and 0.012 for $\mathrm{Sa}\left(T^{*}\right)$ associated with $10 \%$ in 50 years probability of exceedance); at longer return periods (higher spectral amplitudes), the discrepancy becomes larger, with results corresponding to $T^{*}=T_{1}$ and $2 T_{1}$ showing higher median PSDR than $T_{2}$ and $T_{3}$ (e.g., about $400 \%$ difference between 0.048 and 0.012 for $\mathrm{Sa}\left(T^{*}\right)$ associated with $2 \%$ in 50 years probability of exceedance, see Figure $\underline{1}(\mathrm{a})$ ). At shorter return periods, the median PFA shows a slight discrepancy among all the conditioning periods; at longer return periods, the discrepancy becomes larger, with $2 T_{1}$ and $T_{1}$ showing lower median PFA than $T_{2}$ and $T_{3}$ (e.g., 0.404 vs 0.731 for $\mathrm{Sa}\left(T^{*}\right)$ associated with $2 \%$ in 50 years probability of exceedance, see Figure $\underline{1}(\mathrm{c})$ ). The probability of collapse also differs more at longer return periods, with $2 T_{1}$ and $T_{1}$ showing much higher probability of collapse than $T_{2}$ and $T_{3}$ (e.g., 0.4 vs 0.15 for $\mathrm{Sa}\left(T^{*}\right)$ associated with $2 \%$ in 50 years probability of exceedance, see Figure $\underline{1}(\mathrm{e})$ ). Similar collapse probability results as a function of return period are shown in Figure $\underline{5}$ of [27]. As illustrated in Figure $\underline{2}(a)$ in the companion paper [2]], the spectral shape of the CMS becomes more peaked at higher intensity levels (longer return periods). In addition, as illustrated in Figure $\underline{2}$ (b) in the companion paper []ㅡ, the spectral shape of the CMS peaks at the respective conditioning period for a given intensity level. Because an $\varepsilon$ value of 0 will result in the same spectral shape for the CMS at all conditioning periods but $\varepsilon$ values increase as intensity levels increase, it is expected that the spectral shapes of the CMS for various conditioning periods differ more at higher intensity levels, driving a larger discrepancy among structural response obtained using the CS at various conditioning periods.

Over the range of return periods, $T_{1}$ gives the highest median PSDR (Figure $\underline{1}(\mathrm{a})$ ) and the lowest logarithmic standard deviation of PSDR (Figure $\underline{1}(\mathrm{~b})$ ), whereas $T_{3}$ seems to give the highest median PFA (Figure $\underline{1}(\mathrm{c})$ ) and the lowest logarithmic standard deviation of PFA (Figure $\underline{1}(\mathrm{~d})$ ). If we compare the PSDR response (Figure $\underline{1}(\mathrm{a})$ ) with the target CS at the $2 \%$ in 50 years intensity level (or a return period of 2475 years) from Figure 2(b) in the companion paper [1], it is apparent that the analysis using the CS with $T^{*}=2.6 \mathrm{~s}$ produces the

Earthquake Engineering \& Structural Dynamics, Vol. 42, No. 12 (October 10, 2013): pg. 1867-1884. DOI. This article is (C) Wiley and permission has been granted for this version to appear in e-Publications@Marquette. Wiley does not grant permission for this article to be further copied/distributed or hosted elsewhere without the express permission from Wiley. 
largest responses, followed by those using the CS with $T^{*}=5 \mathrm{~s}$, $T^{*}=0.85 \mathrm{~s}$, and $T^{*}=0.45 \mathrm{~s}$, which is comparable with the order of the spectral values with the CS near $2.6 \mathrm{~s}$ (highest spectral values for $2.6 \mathrm{~s}$ followed by $5,0.85$, and $0.45 \mathrm{~s}$ ). Similarly, if we compare the PFA response with the target CS at the $2 \%$ in 50 years intensity level (Figure $\underline{2}(\mathrm{~b})$ in the companion paper [ㄹ] ), the highest responses are produced by the $T^{*}=0.45 \mathrm{~s}$ spectrum followed by the spectra with $T^{*}$ of $0.85,2.6$, and $5 \mathrm{~s}$, which is comparable with the order of the spectral values with the CS near $0.45 \mathrm{~s}$. The logarithmic standard deviations for PFA (Figure 1 (d)) follow the reverse order (compared with median PFA responses) of $5,2.6,0.85$, and $0.45 \mathrm{~s}$. For this structure, $\mathrm{Sa}(0.45 \mathrm{~s})$ seems to be most highly correlated with PFA responses and thus a relatively good predictor of PFA. Taghavi and Miranda [28] show that PFA is strongly dominated by higher modes and that in many cases PGA was strongly correlated with PFA. On the contrary, PSDR responses seem to be most correlated with Sa at periods near $2.6 \mathrm{~s}$ (between 2.6 and $5 \mathrm{~s}$ ). The order of structural response values with respect to various conditioning periods is reversed for PSDR and PFA, illustrating different important periods for different EDPs. For probability of collapse predictions (Figure $\underline{1}(\mathrm{e})$ ), results conditioned on $T^{*}=5 \mathrm{~s}$ show the lowest dispersion in the collapse fragility curve, followed by $2.6,0.85$, and $0.45 \mathrm{~s}$, demonstrating that $\mathrm{Sa}(5 \mathrm{~s})$ is most correlated with collapse prediction. This is consistent with previous observations [e.g., [28-30]] that collapse is most closely related to a lengthened period for long returnperiod ground motions that induce nonlinear behavior in the structure, whereas PSDR is often correlated with first-mode response even when the response is nonlinear.

As seen from the results of the median and logarithmic standard deviation of PSDR and PFA and the probability of collapse, intensitybased assessments depend on the choice of the conditioning period for a given return period. Longer periods can be important for PSDR and collapse, whereas higher-mode periods can be important for PFA.

\section{Alternative Target Spectra}

To determine what ground motions would be appropriate for structural analysis, we first need to specify the target response

Earthquake Engineering \& Structural Dynamics, Vol. 42, No. 12 (October 10, 2013): pg. 1867-1884. DOI. This article is (C) Wiley and permission has been granted for this version to appear in e-Publications@Marquette. Wiley does not grant permission for this article to be further copied/distributed or hosted elsewhere without the express permission from Wiley. 
spectrum in the context of this work. In this section, in addition to the previously considered CS, we consider the UHS that is defined as having Sa with an equal probability of exceedance at all periods and the CMS. Depending on the choice of target spectrum, ground motions would be selected and scaled differently, therefore impacting conclusions regarding structural performance.

\subsection{Uniform hazard spectrum and conditional mean spectrum}

The UHS can be obtained directly from seismic hazard curves at various periods, whereas the computation of the CMS involves computing the mean of the CS (without the variance) as presented in Equation 2 of the companion paper [2]. With the target spectrum identified and computed, ground motions can then be selected from a ground motion database and scaled to match the target spectrum. Individual ground motions are selected via [31] such that the sum of squared errors between their response spectra and the target spectrum mean and variance (while setting the variance of the target spectrum to be zero) is minimized.

To illustrate, let us revisit the $2 \%$ in 50 year intensity level associated with $\mathrm{Sa}(2.6 \mathrm{~s})$. Sets of 40 ground motions are selected to match the UHS, the CMS, and the CS in Figures $\underline{2}(a)-(c)$, respectively. The ground motions selected to match the UHS generally result in higher spectral values on average as the UHS is an envelope of CMS at multiple conditioning periods. The ground motions in Figures $\underline{2}(a)$ and (b) show a lower standard deviation than those in Figure $\underline{2}$ (c) where the distribution of the target spectrum (both mean and variance) is matched. The same procedure is repeated to select ground motions for other intensity levels and periods.

\subsection{Impact of target spectra on intensity-based assessments}

To evaluate the impact of target spectra on intensity-based and risk-based assessments, additional structural analyses can be performed using ground motions selected to match the UHS and CMS. Intensity-based calculations for PSDR, PFA, and probability of collapse 
performed using the CS in the previous section are now repeated here for the other two target spectra, and results are shown in Figure $\underline{3}$. Figures $\underline{3}$ (a) and (b) show the median PSDR and logarithmic standard deviation of non-collapse PSDR for cases with less than $50 \%$ collapse, respectively; Figures $\underline{3}$ (c) and (d) show the median and logarithmic standard deviation of PFA, respectively; Figure $\underline{3}(\mathrm{e})$ shows the probability of collapse. Several observations can be made from Figure $\underline{3}$ and Table $\underline{2}$. First, as expected, the UHS-matched ground motions almost always produce larger median responses than the CSmatched and CMS-matched ground motions with an equivalent return period. The differences are sometimes not large relative to the CMS ground motions at a specific conditioning period. Second, however, the CMS conditioning period associated with the largest median response is not constant over all cases considered. For the PSDR results in Figure $\underline{3}(\mathrm{a})$, conditioning on $\mathrm{Sa}$ at the first-mode period produces the largest medians at a given return period, consistent with intuition that PSDR would be dominated by first-mode elastic response and thus a spectrum that has the largest $S a$ amplitude at the first-mode period would produce the largest PSDR. For the PFA results in Figure $\underline{3}$ (c), the conditioning periods associated with large responses are much shorter. The third-mode elastic period produces the highest median values, with the second-mode period producing nearly as large of values and the longer periods producing much lower values; this is consistent with PFA being a higher-mode driven response parameter.

As seen from these results, intensity-based assessments depend on the choice of the conditioning period for the CS and the CMS. For all intensity levels at various conditioning periods, the CMS produce median PSDR and PFA that are similar to the CS, whereas the UHS produces median PSDR and PFA that are higher than the CS; both the CMS and the UHS result in lower logarithmic standard deviation of PSDR and PFA than the CS. This is explained by the fact that the CMS and the CS share the same median (logarithmic mean) Sa, and that ground motions selected to match the CS additionally account for the spectral variability unlike those selected to match the UHS and CMS (Figure 2).

Earthquake Engineering \& Structural Dynamics, Vol. 42, No. 12 (October 10, 2013): pg. 1867-1884. DOI. This article is (C) Wiley and permission has been granted for this version to appear in e-Publications@Marquette. Wiley does not grant permission for this article to be further copied/distributed or hosted elsewhere without the express permission from Wiley. 


\subsection{Impact of target spectra on risk-based assessments}

For comparison with the conditional spectrum-based results presented in the companion paper [2]], the risk-based assessment procedure is repeated using additional sets of ground motions selected to match the CMS and the UHS at each $\mathrm{Sa}\left(T^{*}\right)$ level. For both of these target spectra, ground motions were selected to match the target spectra at each amplitude, nonlinear dynamic analyses were performed, and the results were used to compute $P\left(P S D R>y \mid \operatorname{Sa}\left(T^{*}\right)=x\right)$ and repeat the risk-based calculation to obtain $\lambda(P S D R>y)$ (via Equations 5 and 6 in the companion paper $[\underline{2}])$.

Risk-based assessment results from the UHS and CMS ground motions, using $T^{*}=2.6 \mathrm{~s}$ are shown in Figure $\underline{4}(\mathrm{a})$, in comparison with the CS results from the companion paper [2]. In this case, the rate of exceeding large PSDR levels is overestimated when ground motions are selected to match UHS; this finding is consistent with previous observations $[$ e.g., $[10,11]]$ that use of the UHS as a target spectrum leads to conservative estimates of structural response. The CMS ground motions produce comparable estimates with the CS motions in this case.

Figures $\underline{5}(a)$ and (c) show the distributions of response spectra from these two sets of ground motions. The CMS spectra at short periods (seen in Figure $\underline{5}(\mathrm{c})$ ) are deficient at high amplitudes relative to the target hazard curves, because variability in the spectra are omitted here. The UHS spectra in Figure $\underline{5}(a)$ are higher than the CMS results at all periods, and especially at $5 \mathrm{~s}$, which explains the high predicted rates of collapse in Figure $\underline{3}(e)$; they are still slightly low at short periods, because the ground motions have little spectral variability and this somewhat offsets the high mean values of the UHS at those periods.

For a second set of comparisons, Figure $\underline{4}(\mathrm{~b})$ shows CMS and UHS risk-based assessment results, but this time using a conditioning period of $T^{*}=0.45 \mathrm{~s}$. The UHS results are still high relative to CS results and are comparable with the Figure $\underline{4}(\mathrm{a})$ results, because the UHS target is not affected by conditioning period and thus the selected ground motions are similar regardless of conditioning period. The CMS

Earthquake Engineering \& Structural Dynamics, Vol. 42, No. 12 (October 10, 2013): pg. 1867-1884. DOI. This article is (C) Wiley and permission has been granted for this version to appear in e-Publications@Marquette. Wiley does not grant permission for this article to be further copied/distributed or hosted elsewhere without the express permission from Wiley. 
results, however, are very low relative to the other results. The reason for this is apparent in Figures $\underline{5}(b)$ and (d), which show the distribution of response spectra from these two sets of ground motions. The ground motions selected on the basis of the CMS spectra are extremely deficient in high-amplitude $S a$ at $T=2.6$ and $5 \mathrm{~s}$, meaning that there are few ground motions in the selected set that are capable of causing collapse of this structure.

To examine the combined effects of conditioning periods and target spectra, risk-based assessments of PSDR for the CMS are repeated for the other two conditioning periods (in addition to the two conditioning periods demonstrated earlier) and are shown together with the results from the CS and the UHS in Figure $\underline{6} a$ and Table $\underline{3}$. While the ground motions selected on the basis of the CS at all four conditioning periods show similar PSDR hazard results (e.g., CS results in an annual rate of $P S D R>2 \%$ in the range of $6.46 \times 10^{-4}$ to $9.42 \times 10^{-4}$ ), the ground motions selected on the basis of the CMS at the four conditioning periods show differing PSDR hazard results, with the results based on $T^{*}=2.6 \mathrm{~s}$ showing the highest values (e.g., CMS based on $T^{*}=2.6 \mathrm{~s}$ results in an annual rate of $P S D R>2 \%=8.55 \times 10^{-4}$, which is within $10 \%$ of CS results based on $T^{*}=2.6 \mathrm{~s}$ ) and the results based on $T^{*}=5 \mathrm{~s}$ showing the second highest values but the results based on $T^{*}=0.85 \mathrm{~s}$ and $T^{*}=0.45 \mathrm{~s}$ showing values that are much lower than those from the CS (e.g., CMS based on $T^{*}=0.45 \mathrm{~s}$ results in an annual rate of $P S D R>2 \%=2.35 \times 10^{-4}$, which is $301 \%$ lower than that of CS results based on $T^{*}=2.6 \mathrm{~s}$ ). This illustrates the difference between the CS results and the CMS results and shows that the CMS results will deviate most from the CS results while using a conditioning period that is not a good predictor for the structural response of interest. The ground motions selected on the basis of the UHS, however, results in higher PSDR hazard (e.g., UHS results in an annual rate of $P S D R>2 \%=1.29 \times 10^{-3}$, which is $37 \%$ higher than that of CS results based on $T^{*}=2.6 \mathrm{~s}$ ) than those from the CS and the CMS.

Similarly, risk-based assessments of PFA for the CS in the companion paper [2] are now repeated for the CMS and the UHS and are shown in Figure $\underline{6}(\mathrm{~b})$ and Table $\underline{3}$. Again, while the ground motions selected on the basis of the CS at all four conditioning periods show similar PFA hazard results, the ground motions selected on the basis of

Earthquake Engineering \& Structural Dynamics, Vol. 42, No. 12 (October 10, 2013): pg. 1867-1884. DOI. This article is (C) Wiley and permission has been granted for this version to appear in e-Publications@Marquette. Wiley does not grant permission for this article to be further copied/distributed or hosted elsewhere without the express permission from Wiley. 
the CMS at the four conditioning periods show differing PFA hazard results, with the results based on $T^{*}=0.45 \mathrm{~s}$ showing the highest values (which are comparable with CS results) and the results based on $T^{*}=0.85$ showing the second highest values but the results based on $T^{*}=2.6 \mathrm{~s}$ and $T^{*}=5 \mathrm{~s}$ showing values that are much lower than those from the CS. The ground motions selected on the basis of the UHS results in higher PFA hazard than those from the CS and the CMS.

As seen from the PSDR hazard and PFA hazard calculations, risk-based assessments are relatively insensitive to the choice of the conditioning period for the CS, but sensitive to the choice of the conditioning period for the CMS. Compared with the CS, the CMS typically underestimate structural response hazard (although the unconservatism may not be significant if $\mathrm{Sa}$ at the conditioning period is a good predictor of the EDP of interest), whereas the UHS overestimates structural response hazard for both PSDR and PFA hazards. The underestimation in the CMS results is a result of omission of spectral variability at periods away from the conditioning period. The overestimation in the UHS results is because of the higher spectral values in the UHS at periods other than the conditioning period.

\section{Additional Structures}

To verify the observations earlier more generally, 11 additional structures were analyzed using the same procedure with ground motions selected to match CS. Perimeter frame and space frame structures with heights from 1 to 20 stories, all originally designed as part of the FEMA P695 project [17], were considered. PSDR and PFA predictions were considered, for both risk-based and intensity-based assessments in all structures. Alternative target spectra were also considered for one of the additional structures, a four-story perimeter frame. All structures were located at the same Palo Alto site used earlier, and Sa with the same exceedance probabilities were considered.

Conditioning periods for CS were $T_{1}, T_{2}, T_{3}$, and $2 T_{1}$ (except in the case of the very short structures, where $T_{2}$ and $T_{3}$ were not considered in some cases). For each conditioning period and spectral amplitude, 40 recorded ground motions were selected and scaled such that their spectra matched target CS. Additional sets of ground 
motions were selected in some cases to match a CS with an inflated conditional standard deviation, as was performed with the $T^{*}=0.45 \mathrm{~s}$ (higher modes) case for PSDR and with the $T^{*}=2.6$ and $5 \mathrm{~s}$ (longer periods) cases for PFA in the 20-story perimeter frame structure illustrated in the companion paper [ㄹ]

Let us look at another example structure, a four-story perimeter frame, denoted Building 1008 in the recent FEMA P695 project [17]. The first three elastic modal periods are $0.91,0.29$ and $0.17 \mathrm{~s}$. Results related to ground motions selected using CS are shown in Figures $\underline{7}$ and $\underline{8}$ for this structure. Conditional standard deviation inflation significantly improved the agreements for the PSDR hazard among all four conditioning periods (Figures $\underline{7}$ (a) versus (b)). This again demonstrates the relative insensitivity of risk-based assessments to the choice of conditioning period when ground motions are carefully selected to ensure hazard consistency. However, the choice of conditioning period, again, can substantially impact structural response estimates, as illustrated in Figure $\underline{8}$. For the four-story perimeter frame, PFA seems to be most dominated by the second-mode period, $T_{2}$ (compared with the third-mode period, $T_{3}$ for the 20-story perimeter frame and other 8-story and 12-story frames not presented here), as indicated in Figures $\underline{8}(\mathrm{c})$ and (d). The first-mode period, $T_{1}$ continues to be important for PSDR (Figures $\underline{8}(\mathrm{a})$ and (b)), and the lengthened period, $2 T_{1}$, continues to be important for collapse (Figure $\underline{8}(\mathrm{e})$ ). The difference in logarithmic standard deviation of PSDR is now quite significant between the shorter and longer periods (Figure $\underline{8}(\mathrm{~b})$ ).

In all analysis cases, consistency of risk-based assessment results across conditioning periods was again observed, whereas intensity-based assessment results varied as the conditioning period varied, for a given structure. These results thus provide further empirical confirmation of the findings described in detail earlier. The large set of results supporting these statements is omitted from this paper for brevity but is documented in Appendix A of [32].

Earthquake Engineering \& Structural Dynamics, Vol. 42, No. 12 (October 10, 2013): pg. 1867-1884. DOI. This article is (C) Wiley and permission has been granted for this version to appear in e-Publications@Marquette. Wiley does not grant permission for this article to be further copied/distributed or hosted elsewhere without the express permission from Wiley. 


\section{Implications for Building Codes and Performance-Based Earthquake Engineering}

Both risk-based and intensity-based assessments are investigated, along with evaluations of such target spectra as the CS, the CMS, and the UHS. The findings here have important implications on the choice of conditioning period and target spectrum for buildingcode-type check and performance-based earthquake engineering, as discussed later.

\section{1 Risk-based assessments}

For risk-based assessments (typically used in performancebased earthquake engineering), the CS (including variability) is a recommended target spectrum. Results are relatively insensitive to the choice of conditioning period, $T^{*}$, but the choice of an efficient $T^{*}$ (closely related to the structural response of interest) may reduce the number of required structural analyses. If the CMS is used, the structural response hazard is typically underestimated, especially for conditioning periods that are further away from the period closely related to the structural response of interest. In contrast, if the UHS is used, the structural response hazard estimate is usually conservative.

\subsection{Intensity-based assessments}

For intensity-based building-code-type checks, the CMS and the CS are both defensible target spectra. The choice of CS or CMS depends on the goal of the analyses. If the median structural response is of interest, either spectrum can be used-the CMS can be an efficient choice for this purpose. If the full distribution of structural response is of interest, the CS should be used to capture the variability in structural response. Results will fully depend on the conditioning period, $T^{*}$, because different $T^{*}$ implies a different question being asked. If the conditioning period, $T^{*}$, most closely relates to the structural response parameter of interest is known, that $T^{*}$ alone may be sufficient to evaluate the specified structural response. Such conditioning period is often associated with the lowest dispersion estimate and the highest median estimate of structural response. 
NOT THE PUBLISHED VERSION; this is the author's final, peer-reviewed manuscript. The published version may be accessed by following the link in the citation at the bottom of the page.

\subsection{Selection of target spectrum}

In the absence of more complete guidance on 'what the right question is', a tentative recommendation for building-code-type checks is to use a conditioning period, $T^{*}$, that results in the highest response. Multiple $T^{*}$ and conditional spectra or conditional mean spectra may be needed if multiple responses are of interest. For instance, if the objective is to limit first-mode sensitive response parameters (e.g., PSDR), a single spectrum conditioned at $T_{1}$ may be sufficient; if the goal is to additionally ensure that higher-modesensitive response parameters (e.g., PFA or member forces) are limited, a second higher-mode spectrum may be needed.

Unless conservatism is intentional, use of the UHS is not recommended, because ground motions associated with a UHS are typically not consistent with the ground motion hazard for which they are selected. If future building codes allow use of conditional spectra or conditional mean spectra in place of a UHS, the average values of responses computed in those checks may be reduced even if the target return period of the ground motion is unchanged because of the eliminated conservatism of the UHS target. The level of reduction depends upon the extent to which the response parameter of interest is associated with spectral values at multiple periods; structures that behave like elastic single-degree-of-freedom oscillators are sensitive only to Sa at a single period and thus the responses from CS-matched or UHS-matched motions conditioned on that period will be identical. Conversely, structural response parameters sensitive to multiple modes of excitation or to significant nonlinearity (such as collapse, where the structure's effective period lengthens) may experience reduced responses from CS-matched motions relative to UHS-matched motions with the same intensity at the conditioning period.

\subsection{Linking performance goals and design checks}

Risk-based assessments are often used in performance-based earthquake engineering, whereas intensity-based assessments often resemble those from the building-code type design checks. There is a recent shift in building codes towards risk-based assessments (e.g., the collapse risk performance goal in ASCE/SEI 7-10 [4]]), but the 
design checks are still primarily intensity-based (i.e., assessing structural response at a single intensity level). In the case of ASCE/SEI $7-10$, the stated objective of the design requirements is to achieve building designs that have less than a $1 \%$ probability of collapse in 50 years, and the intensity-based assessment (and corresponding acceptance criteria) is implicitly intended to measure whether this objective is being achieved.

The findings here imply a missing link between the implicit performance goals and the explicit design checks that needs to be reconciled. A detailed study to determine whether the current intensity-based design checks are optimal for and consistent with the risk-based performance goals would be valuable. Such a study is needed to better determine the appropriate intensity-based question that ASCE 7 should be asking (to be consistent with its fundamental goal of acceptable collapse risk).

\subsection{Implications for analysis of 3-D structural models}

The results earlier are obtained by analyzing 2-D structural models subjected to a single component of ground motion, and so some thought is needed to translate these observations into conclusions for 3-D structural models subjected to multicomponent ground motions. The findings earlier provide some reassurance that risk-based assessments can be robustly performed for 3-D structural models as long as hazard-consistent ground motions are used for the analysis. For the 3-D case, hazard consistency requires that ground motions have Sa distributions consistent with hazard curves at all periods and orientations of interest. This should be the case regardless of the choice of response spectra definition (i.e., arbitrary component, geometric mean, or maximum component). This hypothesis follows from the earlier results showing consistent risk-based results if ground motions have hazard consistent spectra at multiple periods and extending it to spectra at multiple orientations. This thinking is also consistent with earlier research on this topic [33]. Further work to empirically verify this hypothesis, and to develop appropriate intensitybased assessment rules, would be valuable.

Earthquake Engineering \& Structural Dynamics, Vol. 42, No. 12 (October 10, 2013): pg. 1867-1884. DOI. This article is (C) Wiley and permission has been granted for this version to appear in e-Publications@Marquette. Wiley does not grant permission for this article to be further copied/distributed or hosted elsewhere without the express permission from Wiley. 
NOT THE PUBLISHED VERSION; this is the author's final, peer-reviewed manuscript. The published version may be accessed by following the link in the citation at the bottom of the page.

\section{Conclusions}

This paper has presented a study on the sensitivity of intensitybased assessment (which estimates structural response given ground motions whose intensity measure amplitudes have a specific exceedance probability) results to the choice of conditioning period when the CS is used as a target for ground motion selection and scaling. This paper has also presented a study of the sensitivity of both risk-based and intensity-based assessments to the choice of target spectrum, including evaluation of the UHS and the CMS. The primary structure studied was a 20-story concrete frame structure assumed to be located in Palo Alto, California, using a structural model with strength and stiffness deterioration that is believed to reasonably capture the responses up to the point of collapse because of dynamic instability.

The study showed that the choice of conditioning period for the CS can substantially impact structural response estimates for an intensity-based assessment, but that risk-based assessments are relatively insensitive to the choice of conditioning period in the CS (given that the ground motions are carefully selected to ensure hazard consistency). For intensity-based assessments, use of the CMS, instead of the CS, does not significantly affect the median response estimates but does decrease both the dispersion of the response and the probability of collapse distribution. For risk-based assessments, use of the CMS, instead of the CS, typically results in underestimation of structural response hazard because of the omission of spectral variability in the selected ground motions, whereas use of the UHS results in overestimation in the structural response hazard. These findings have potentially important implications for seismic assessments using the CS in future building code and performancebased earthquake engineering applications.

An important issue regarding conditioning period arises when an intensity-based assessment is being used, and the purpose is to compute the mean or median response associated with an $\mathrm{Sa}\left(T^{*}\right)$ having a specified probability of exceedance (e.g., for a building-codetype check). In this extremely common case, the response prediction will always change depending upon the choice of conditioning period. 
This comes from the fact that the choice of conditioning period is an inherent part of the problem statement, and so in this case changing the conditioning period changes the question that is being asked. For example, computing the median drift response for a building subjected to a $2 \%$ in 50 year exceedance $S a(1 \mathrm{~s})$ is not the same as computing the median drift response for a building subjected to a $2 \%$ in to 50 year exceedance $\mathrm{Sa}(2 \mathrm{~s})$; these are two different questions. Resolution of this issue is not obvious, but likely lies in identifying a conditioning period and performance check that, when passed, confirms satisfactory reliability of the structural system.

Additional evaluations were completed for 11 other structures. Although not reported in this paper, they are available in Appendix A of [32]; these additional analyses confirm the generality of the conclusions made in this paper and collectively provide a more complete picture of the relationship between careful ground motion selection and robust structural response results.

\section{Acknowledgements}

The authors thank Brendon Bradley, Eduardo Miranda, Gregory Deierlein, and an anonymous reviewer for their helpful reviews of the manuscript. The authors also acknowledge the contributions of Jared DeBock and Fortunato Enriquez in conducting the structural analyses used in this study. This work was part of a larger project on ground motion selection []]. It was supported in part by the NEHRP Consultants Joint Venture (a partnership of the Consortium of Universities for Research in Earthquake Engineering and Applied Technology Council), under Contract SB134107CQ0019, Earthquake Structural and Engineering Research, issued by the National Institute of Standards and Technology, for project ATC-82. Any opinions, findings, and conclusions or recommendations expressed in this material are those of the authors and do not necessarily reflect those of the NEHRP Consultants Joint Venture.

\section{References}

1 ATC. Guidelines for seismic performance assessment of buildings, ATC-58 100\% draft. Technical Report, Applied Technology Council: Redwood City, California, 2011.

2 Lin T, Haselton CB, Baker JW. Conditional spectrum-based ground motion selection. Part I: Hazard consistency for risk-based assessments, Earthquake Engineering \& Structural Dynamics 2013. DOI 10.1002/eqe.2301.

Earthquake Engineering \& Structural Dynamics, Vol. 42, No. 12 (October 10, 2013): pg. 1867-1884. DOI. This article is (C) Wiley and permission has been granted for this version to appear in e-Publications@Marquette. Wiley does not grant permission for this article to be further copied/distributed or hosted elsewhere without the express permission from Wiley. 
NOT THE PUBLISHED VERSION; this is the author's final, peer-reviewed manuscript. The published version may be accessed by following the link in the citation at the bottom of the page.

3 ICC. International building code 2003. International Code Council, 2003. 4 ASCE. Minimum Design Loads for Buildings and Other Structures, ASCE 710, American Society of Civil Engineers/Structural Engineering Institute: Reston, VA, 2010.

5 Baker JW.Conditional mean spectrum: tool for ground motion selection, Journal of Structural Engineering 2011; 137(3):322-331.

6 NIST. Selecting and scaling earthquake ground motions for performing response-history analyses, NIST GCR 11-917-15. Technical Report, prepared by the NEHRP Consultants Joint Venture for the National Institute of Standards and Technology: Gaithersburg, Maryland, 2011.

7 CEN. Eurocode 8: design of structures for earthquake Resistance-Part 1: general rules, seismic actions and rules for buildings. European Standard NF EN 1998-1:2004, Comité Européen de Normalisation: Brussels, Belgium, 2004.

8 Reiter L.Earthquake Hazard Analysis: Issues and Insights, Columbia University Press: New York, 1990.

9 McGuire RK.Probabilistic seismic hazard analysis and design earthquakes: closing the loop, Bulletin of the Seismological Society of America 1995; 85(5): 1275-1284.

10 Naeim F, Lew M.On the use of design spectrum compatible time histories, Earthquake Spectra 1995; 11(1):111-127.

11 Bommer JJ, Scott S, Sarma S. Hazard-consistent earthquake scenarios, Soil Dynamics and Earthquake Engineering 2000; 19:219-231.

12 Baker JW, Cornell CA.Spectral shape, epsilon and record selection, Earthquake Engineering \& Structural Dynamics 2006; 35(9):10771095, DOI 10.1002/eqe.571.

13 Somerville $P G$, Hamburger RO.Development of ground motion time histories for design, Seismic Mitigation for Museum Collection: Papers from the J. Paul Getty Museum - National Museum of Western Art (Tokyo) Jointly Sponsored Symposium: Tokyo, Japan, 2009; 7 pp.

14 Abrahamson NA, Al Atik L.Scenario spectra for design ground motions and risk calculation, 9th US National and 10th Canadian Conference on Earthquake Engineering: Toronto, Canada, 2010; Paper Number 1896, $12 \mathrm{pp}$.

15 Gulerce $Z$, Abrahamson NA.Site-specific design spectra for vertical ground motion, Earthquake Spectra 2011; 27(4):1023-1047.

16 Somerville PG, Thio HK.Development of ground motion time histories for seismic design, Proceedings of the Ninth Pacific Conference on Earthquake Engineering: Auckland, New Zealand, 2011; Paper Number 208, 8 pp.

17 ATC. Quantification of building seismic performance factors, FEMA P695. Technical Report, Applied Technology Council: Redwood City, California, 2009.

Earthquake Engineering \& Structural Dynamics, Vol. 42, No. 12 (October 10, 2013): pg. 1867-1884. DOI. This article is (C) Wiley and permission has been granted for this version to appear in e-Publications@Marquette. Wiley does not grant permission for this article to be further copied/distributed or hosted elsewhere without the express permission from Wiley. 
NOT THE PUBLISHED VERSION; this is the author's final, peer-reviewed manuscript. The published version may be accessed by following the link in the citation at the bottom of the page.

18 Haselton CB, Deierlein GG.Assessing seismic collapse safety of modern reinforced concrete moment frame buildings. Technical Report 2007/08, Pacific Earthquake Engineering Research Center: Berkeley, CA, 2007.

19 Shome $N$, Cornell CA.Probabilistic seismic demand analysis of nonlinear structures. Technical Report RMS-35, RMS Program: Stanford CA, 1999.

20 Song J, Ellingwood BR.Seismic reliability of special moment steel frames with welded connections: I, Journal of Structural Engineering 1999; 125(4):357-371.

21 Shinozuka M, Feng MQ, Lee J, Naganuma T.Statistical analysis of fragility curves., Journal of Engineering Mechanics 2000; 126(12):1224-1231.

22 Sasani M, Kiureghian AD.Seismic fragility of RC structural walls: displacement approach, Journal of Structural Engineering 2001; 127(2): 219-228.

23 Aslani H, Miranda E.Probability-based seismic response analysis, Engineering Structures 2005; 27(8):1151-1163.

24 Stoica M, Medina RA, McCuen RH.Improved probabilistic quantification of drift demands for seismic evaluation, Structural Safety 2007; 29(2):132-145.

25 Baker JW.Vector-valued ground motion intensity measures for probabilistic seismic demand analysis. P.hD. Thesis, Stanford University, 2005.

26 Straub $D$, Kiureghian AD.Improved seismic fragility modeling from empirical data, Structural Safety 2008; 30(4):320-336.

27 Bradley BA, Dhakal RP, MacRae GA, Cubrinovski M.Prediction of spatially distributed seismic demands in specific structures: structural response to loss estimation, Earthquake Engineering \& Structural Dynamics 2010; 39(6):591-613, DOI 10.1002/eqe.955.

28 Taghavi S, Miranda E.Response assessment of nonstructural building elements. Technical Report 2003/05, Pacific Earthquake Engineering Research Center: Berkeley, CA, 2003.

29 Haselton CB, Baker JW.Ground motion intensity measures for collapse capacity prediction: choice of optimal spectral period and effect of spectral shape, 8th National Conference on Earthquake Engineering: San Francisco, California, 2006; 10 pp.

30 Bradley BA, Dhakal RP, MacRae GA, Cubrinovski M.Prediction of spatially distributed seismic demands in specific structures: ground motion and structural response, Earthquake Engineering \& Structural Dynamics 2010; 39(5):501-520, DOI 10.1002/eqe.954.

31 Jayaram N, Lin T, Baker JW.A computationally efficient ground-motion selection algorithm for matching a target response spectrum mean and variance, Earthquake Spectra 2011; 27(3): 797-815, DOI 10.1193/1.3608002.

Earthquake Engineering \& Structural Dynamics, Vol. 42, No. 12 (October 10, 2013): pg. 1867-1884. DOI. This article is (C) Wiley and permission has been granted for this version to appear in e-Publications@Marquette. Wiley does not grant permission for this article to be further copied/distributed or hosted elsewhere without the express permission from Wiley. 
NOT THE PUBLISHED VERSION; this is the author's final, peer-reviewed manuscript. The published version may be accessed by following the link in the citation at the bottom of the page.

\section{Lin T.Advancement of hazard-consistent ground motion selection methodology. Ph.D. Thesis, Stanford University, 2012.}

33 Baker JW, Cornell CA. Which spectral acceleration are you using? Earthquake Spectra 2006; 22(2):293-312.

Correspondence to: Ting Lin, Department of Civil and Environmental Engineering, Stanford University, Stanford, CA 94305-4020, U.S.A. E-mail: tinglin@stanford.edu
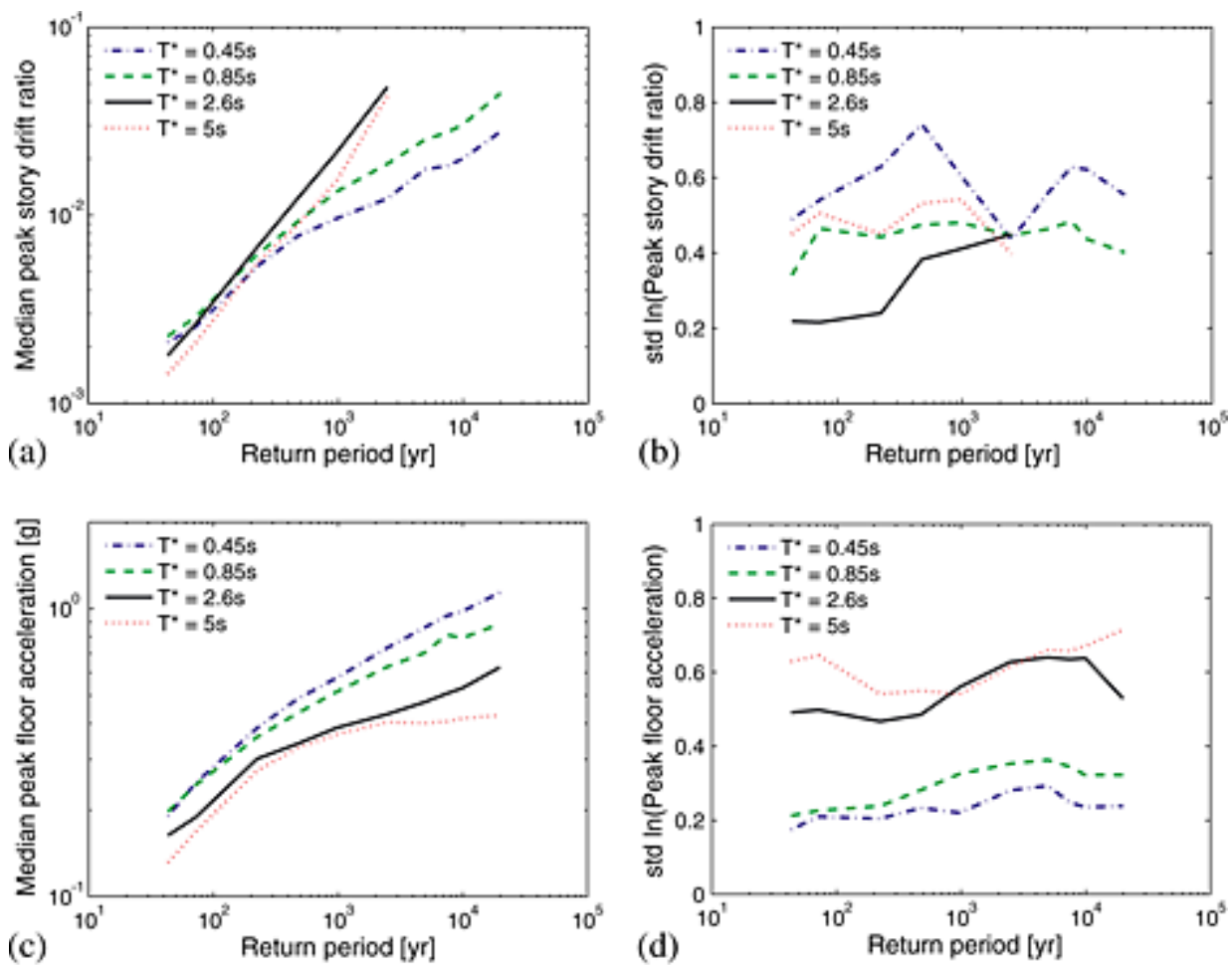

(d)

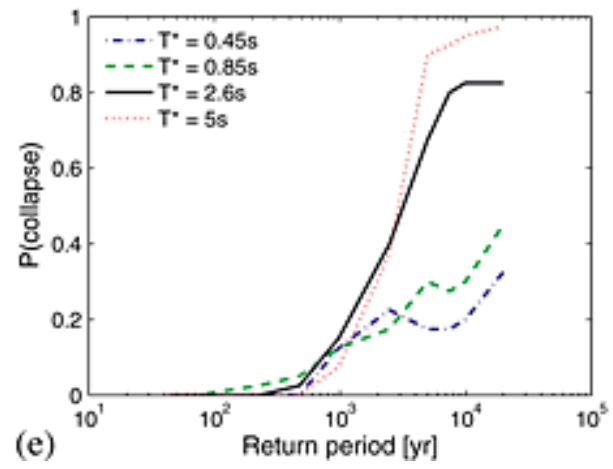

Figure 1.

Statistics of structural responses from intensity-based assessments of the 20-story perimeter frame (Building No.1020) using the CS (a) median PSDR, (b) logarithmic

Earthquake Engineering \& Structural Dynamics, Vol. 42, No. 12 (October 10, 2013): pg. 1867-1884. DOI. This article is (C) Wiley and permission has been granted for this version to appear in e-Publications@Marquette. Wiley does not grant permission for this article to be further copied/distributed or hosted elsewhere without the express permission from Wiley. 
NOT THE PUBLISHED VERSION; this is the author's final, peer-reviewed manuscript. The published version may be accessed by following the link in the citation at the bottom of the page.

standard deviation of PSDR, (c) median PFA, (d) logarithmic standard deviation of PFA, and (e) probability of collapse.

Table 1. Summary of selected structural response results from intensitybased assessments using ground motions selected to match the CS.

\section{Intensity \\ levels}

Median PSDR

Median PFA

Probability of collapse

\section{$0.45 s \quad 0.85 s \quad 2.6 s \quad 5 s \quad 0.45 s \quad 0.85 s \quad 2.6 s \quad 5 s$}

0.45 s 0.85 s $2.6 s \quad 5 s$

1. CS, conditional spectrum; PSDR, peak story drift ratio; PFA, peak floor acceleration.
$50 \%$ in
30 years
0.002
0.002
0.0020 .0010 .191
0.1980 .1640 .1320
0
$10 \%$ in
50 years
0.008
0.009
0.0120 .0090 .487
0.4340 .3400 .3280
$0.05 \quad 0.0250$
$2 \%$ in 50
years
$0.175 \quad 0.4$
0.375
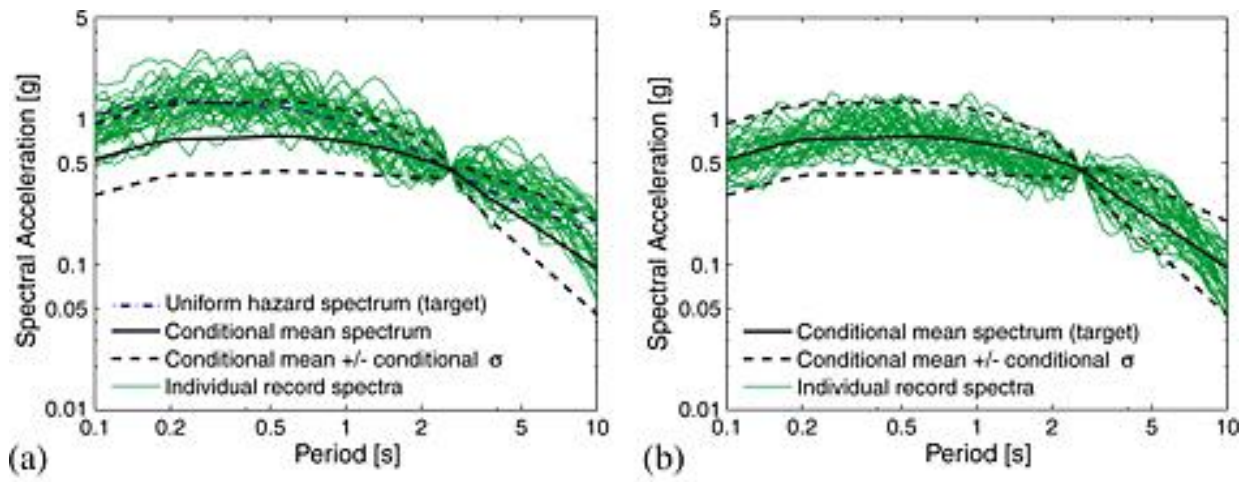

(b)

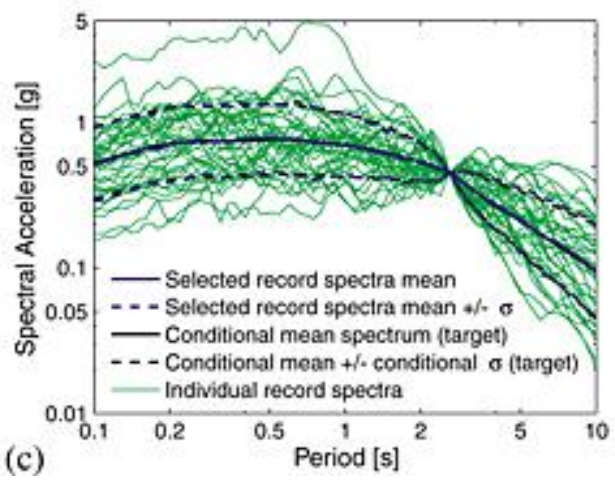

Figure 2.

Response spectra of selected ground motions with (a) UHS, (b) CMS, and (c) CS as target spectra for $\mathrm{Sa}(2.6 \mathrm{~s})$ associated with $2 \%$ in 50 years probability of exceedance for the 20-story perimeter frame (Building No.1020).

Earthquake Engineering \& Structural Dynamics, Vol. 42, No. 12 (October 10, 2013): pg. 1867-1884. DOI. This article is (C) Wiley and permission has been granted for this version to appear in e-Publications@Marquette. Wiley does not grant permission for this article to be further copied/distributed or hosted elsewhere without the express permission from Wiley. 
NOT THE PUBLISHED VERSION; this is the author's final, peer-reviewed manuscript. The published version may be accessed by following the link in the citation at the bottom of the page.
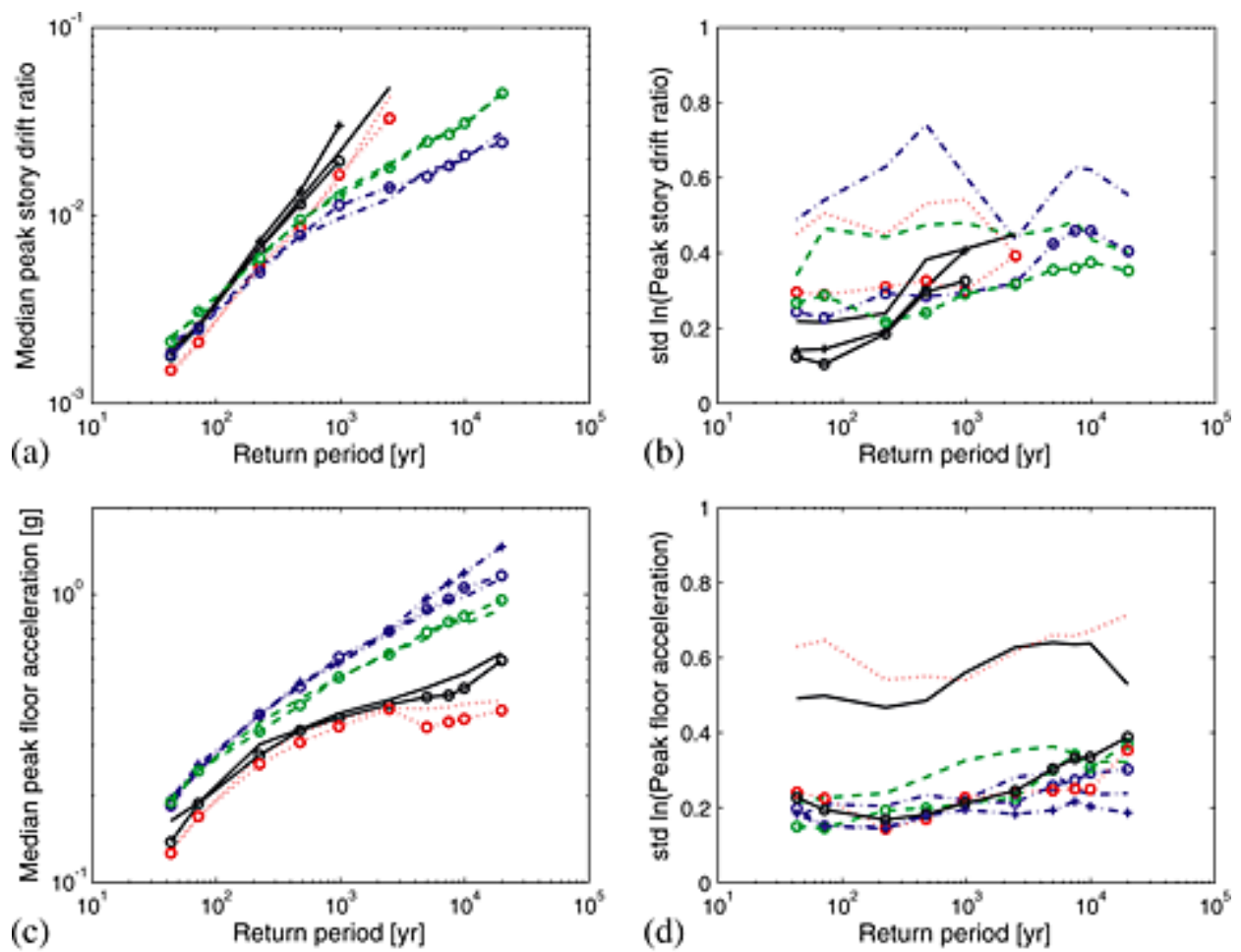

(d)

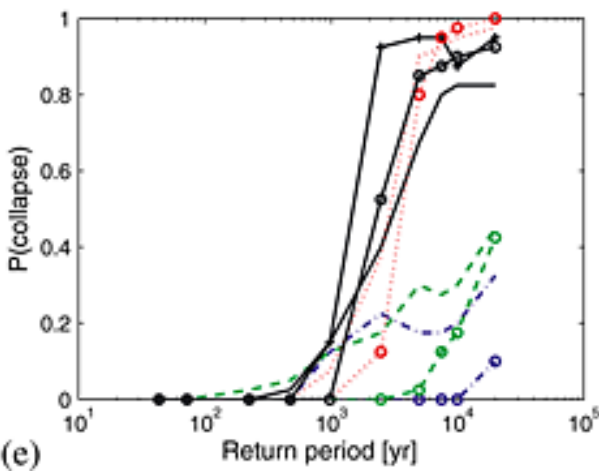

$=-T^{*}=0.45 s_{\text {, }}$ CS

$---T^{*}=0.85 s$, CS

$-T^{*}=2,65, \mathrm{CS}$

….. $\mathbf{T}^{*}=5.5, \mathrm{CS}$

$\rightarrow \mathrm{T}^{*}=2.6 \mathrm{~s}$, UHS

$-\infty T^{*}=0.45$, CMS

$-\theta-T^{*}=0.85$, CMS

- $\mathrm{T}^{*}=5 \mathrm{~s}, \mathrm{CMS}$

$\rightarrow-T^{*}=2.6 s$, CMS

Figure 3.

Statistics of structural responses from intensity-based assessments of the 20-story perimeter frame (Building No.1020) (a) median PSDR, (b) logarithmic standard deviation of PSDR, (c) median PFA, (d) logarithmic standard deviation of PFA, and (e) probability of collapse.

Earthquake Engineering \& Structural Dynamics, Vol. 42, No. 12 (October 10, 2013): pg. 1867-1884. DOI. This article is (C) Wiley and permission has been granted for this version to appear in e-Publications@Marquette. Wiley does not grant permission for this article to be further copied/distributed or hosted elsewhere without the express permission from Wiley. 
NOT THE PUBLISHED VERSION; this is the author's final, peer-reviewed manuscript. The published version may be accessed by following the link in the citation at the bottom of the page.

Table 2. Summary of selected structural response results from intensitybased assessments using ground motions selected to match the CS, the CMS, and the UHS.

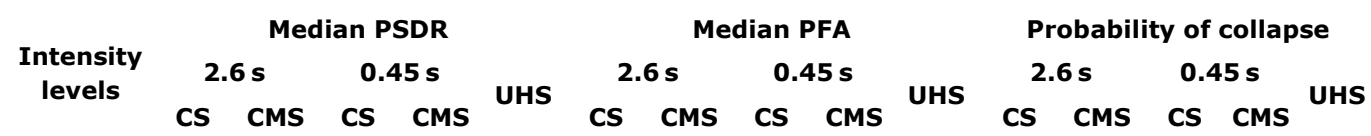

1. CS, conditional spectrum; CMS, conditional mean spectrum; UHS, uniform hazard spectrum; PSDR, peak story drift ratio; PFA, peak floor acceleration.

$50 \%$ in 30 years

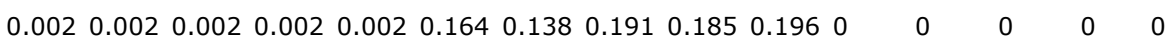

$10 \%$ in

50 years

$2 \%$ in 50 years

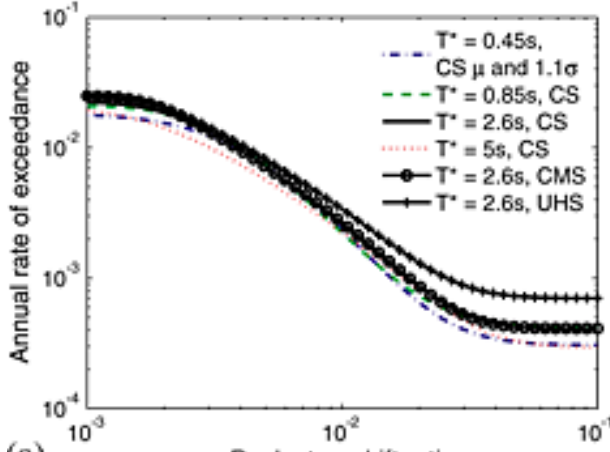

(a)

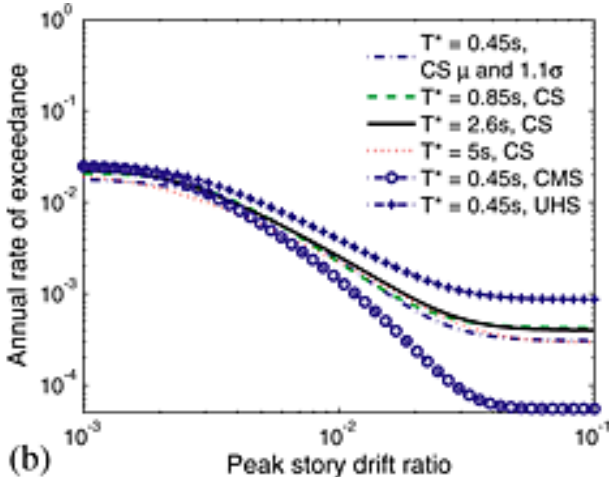

Figure 4.

Risk-based assessments of PSDR of the 20-story perimeter frame (Building No.1020) obtained from ground motions selected to match the CS (all four conditioning periods) as well as the CMS and the UHS for (a) $T^{*}=2.6 \mathrm{~s}$ and (b) $T^{*}=0.45 \mathrm{~s}$.

Earthquake Engineering \& Structural Dynamics, Vol. 42, No. 12 (October 10, 2013): pg. 1867-1884. DOI. This article is (C Wiley and permission has been granted for this version to appear in e-Publications@Marquette. Wiley does not grant permission for this article to be further copied/distributed or hosted elsewhere without the express permission from Wiley. 
NOT THE PUBLISHED VERSION; this is the author's final, peer-reviewed manuscript. The published version may be accessed by following the link in the citation at the bottom of the page.
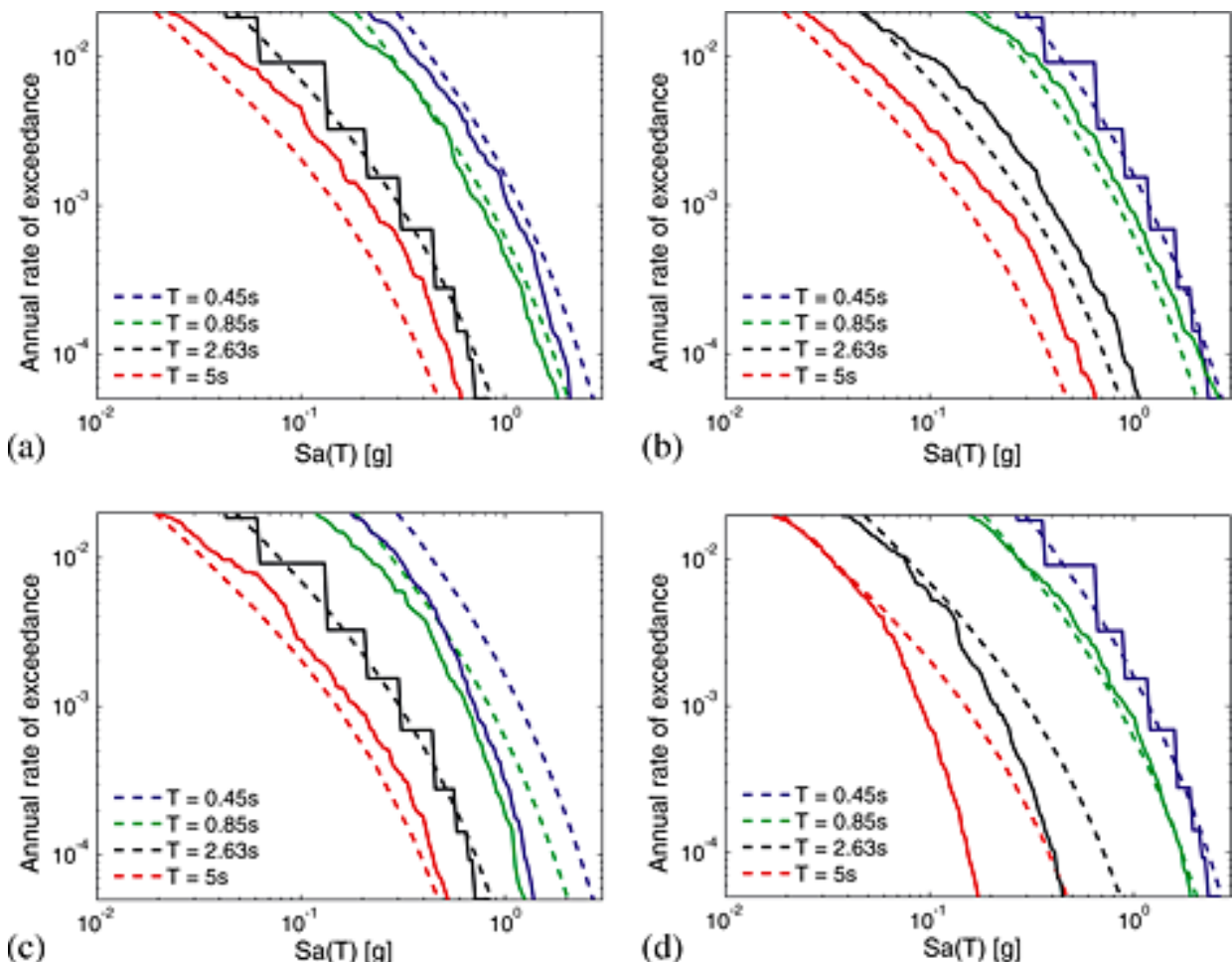

(b)

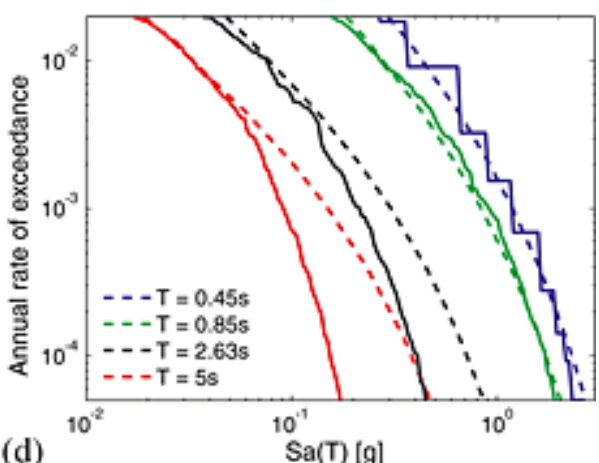

Figure 5.

Sa distribution at four periods for ground motions selected at (a) $T^{*}=2.6 \mathrm{~s}$, UHS; (b) $T^{*}=0.45 \mathrm{~s}$, UHS; (c) $T^{*}=2.6 \mathrm{~s}$, CMS; and (d) $T^{*}=0.45 \mathrm{~s}, \mathrm{CMS}$.
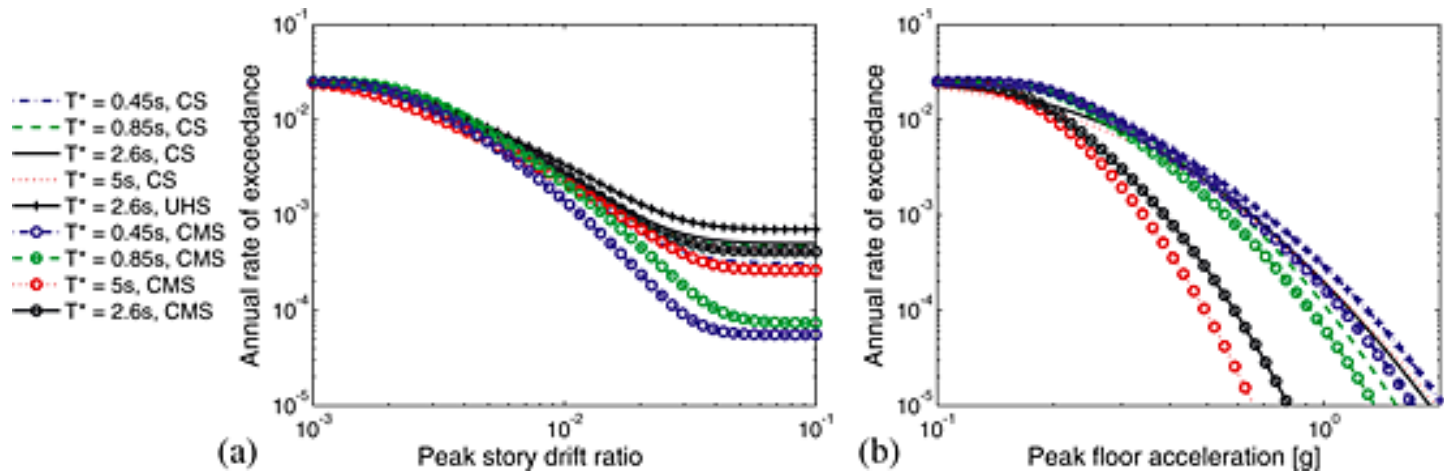

Figure 6.

Risk-based assessments of (a) PSDR and (b) PFA of the 20-story perimeter frame (Building No.1020) obtained from ground motions selected to match the CS, the CMS, and the UHS.

Earthquake Engineering \& Structural Dynamics, Vol. 42, No. 12 (October 10, 2013): pg. 1867-1884. DOI. This article is (C) Wiley and permission has been granted for this version to appear in e-Publications@Marquette. Wiley does not grant permission for this article to be further copied/distributed or hosted elsewhere without the express permission from Wiley. 
NOT THE PUBLISHED VERSION; this is the author's final, peer-reviewed manuscript. The published version may be accessed by following the link in the citation at the bottom of the page.

Table 3. Summary of selected structural response results from intensitybased assessments using ground motions selected to match the CS, the CMS, and the UHS.
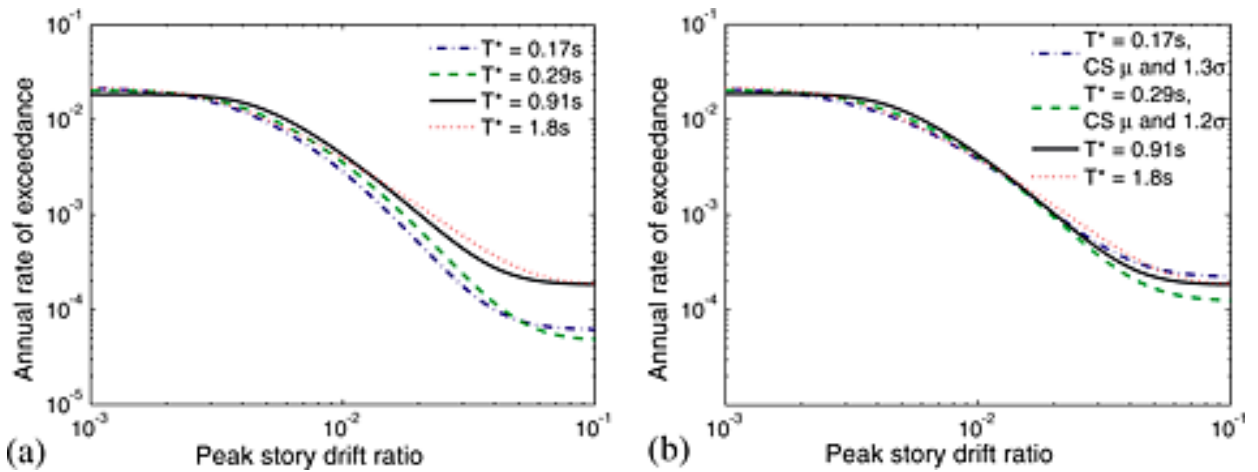

Figure 7.

Risk-based assessments of PSDR of the four-story perimeter frame (Building No.1008) obtained from ground motions with (a) approximate CS with approximate conditional standard deviations and (b) refined CS with inflated conditional standard deviations.

Earthquake Engineering \& Structural Dynamics, Vol. 42, No. 12 (October 10, 2013): pg. 1867-1884. DOI. This article is (C) Wiley and permission has been granted for this version to appear in e-Publications@Marquette. Wiley does not grant permission for this article to be further copied/distributed or hosted elsewhere without the express permission from Wiley. 
NOT THE PUBLISHED VERSION; this is the author's final, peer-reviewed manuscript. The published version may be accessed by following the link in the citation at the bottom of the page.
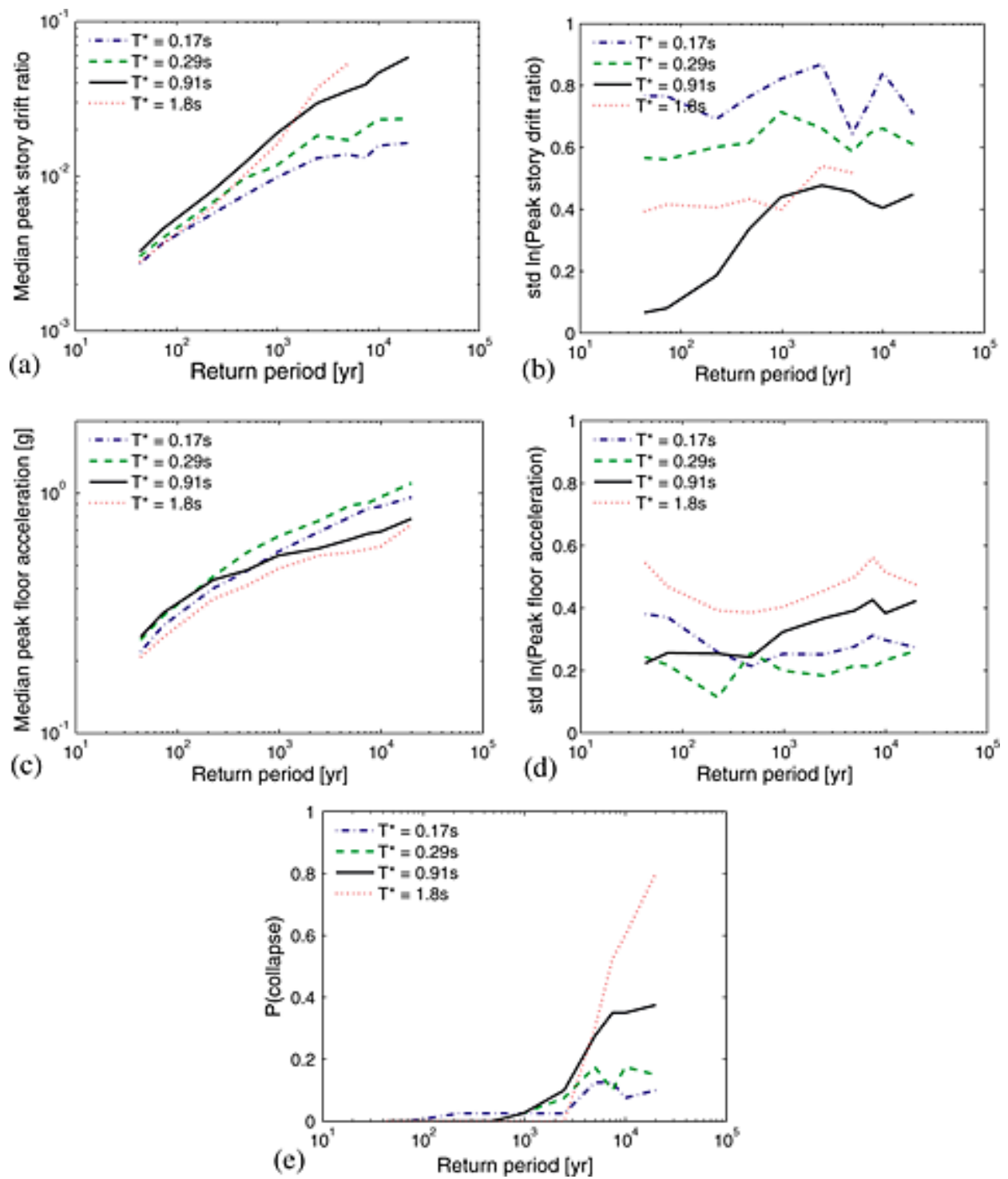

Figure 8.

Statistics of structural responses from intensity-based assessments of the four-story perimeter frame (Building No.1008) using the CS (a) median PSDR, (b) logarithmic standard deviation of PSDR, (c) median PFA, (d) logarithmic standard deviation of PFA, and (e) probability of collapse.

Earthquake Engineering \& Structural Dynamics, Vol. 42, No. 12 (October 10, 2013): pg. 1867-1884. DOI. This article is (C) Wiley and permission has been granted for this version to appear in e-Publications@Marquette. Wiley does not grant permission for this article to be further copied/distributed or hosted elsewhere without the express permission from Wiley. 